\title{
The Path to Implementation of A Clinical Laboratory System in A Developing Country
}

\section{Mentor Ali Ber Lucien ( $\nabla$ lucienmentor@gmail.com )}

Laboratoire National de Santé Publique, Ministère de la Santé Publique et de la Population, Port-au-

Prince

Jean Sakandé

Institut Africain de Santé Publique, Ouagadougou

Chloé Masetti

Fondation Mérieux

Micheline Cicéron

Laboratoire National de Santé Publique, Ministère de la Santé Publique et de la Population, Port-auPrince

\section{Paul Adrien}

Direction d'Épidémiologie, de Laboratoire et de Recherches, Ministère de la Santé Publique et de la Population, Port-au-Prince

\section{Seni Kouanda}

Institut Africain de Santé Publique, Ouagadougou

\section{Michael F. Canarie}

Department of Pediatrics, Yale University School of Medicine, New Haven, CT

\section{Gina Maki}

The Global Health Initiative, Henry Ford Health System, Detroit, MI

\section{Linda M. Kaljee}

The Global Health Initiative, Henry Ford Health System, Detroit, MI

\section{Paul E. Kilgore}

Eugene Applebaum School of Pharmacy, Wayne State University, Detroit, MI

\section{Dana M. Parke}

The Global Health Initiative, Henry Ford Health System, Detroit, MI

\section{Gerard A. Joseph}

Laboratoire National de Santé Publique, Ministère de la Santé Publique et de la Population, Port-auPrince

\section{Elsie Lafosse}

Laboratoire National de Santé Publique, Ministère de la Santé Publique et de la Population, Port-auPrince

\section{Josiane Buteau}


Laboratoire National de Santé Publique, Ministère de la Santé Publique et de la Population, Port-auPrince

\section{Magalie Stanislas}

Laboratoire National de Santé Publique, Ministère de la Santé Publique et de la Population, Port-auPrince

\section{Patrick Dely}

Direction d'Épidémiologie, de Laboratoire et de Recherches, Ministère de la Santé Publique et de la Population, Port-au-Prince

\section{Marcus J. Zervos}

The Global Health Initiative, Henry Ford Health System, Detroit, MI Jacques Boncy

Laboratoire National de Santé Publique, Ministère de la Santé Publique et de la Population, Port-auPrince

\section{Research Article}

Keywords: developing countries, clinical laboratory, network

Posted Date: February 2nd, 2021

DOI: https://doi.org/10.21203/rs.3.rs-151754/v1

License: (c) (i) This work is licensed under a Creative Commons Attribution 4.0 International License. Read Full License 
country

Dana M. Parke ${ }^{6}$, Gerard A. Joseph ${ }^{1}$, Elsie Lafosse ${ }^{1}$, Josiane Buteau ${ }^{1}$, Magalie Stanislas ${ }^{1}$, Patrick

Dely $^{4}$, Marcus J. Zervos ${ }^{6}$, Jacques Boncy ${ }^{1}$.

${ }^{1}$ Laboratoire National de Santé Publique, Ministère de la Santé Publique et de la 
Clinical laboratory system in Haiti

27

\section{Abstract \\ Background}

An effective laboratory system is an essential component of a public health system caring for patients with communicable and non-communicable diseases. Unfortunately, in developing countries this system is often sub-optimal, which negatively impacts health care. This paper describes the current situation of the clinical laboratory sector in Haiti and highlights challenges that exist in Haiti and other developing countries as they try to establish a clinical laboratory system.

\section{Method}

A cross-sectional survey was conducted in 30 laboratories across Haiti from January 19 to February 4, 2016. The laboratories surveyed were public or mixed public-private sector facilities belonging to different levels of the healthcare hierarchy. Labs were visited and directors of the health care institutions, lab managers, and members of their teams were interviewed and National Public Health Laboratory documents and information about the legal framework of the laboratory system was reviewed.

\section{Results}

The National Laboratory of Public Health is the reference lab for the national lab network and plays a key role in epidemiologic surveillance. Investigators felt that that the general conditions in the nation's labs (83\%) are good, but numerous deficiencies are identified. Electricity is often limited and $86 \%$ of facilities have mixed energy system. Bacterial cultures and susceptibilities are not performed. Most of the lab technologists $(88.2 \%)$ have received only 2 two-year training certificates, while only the remainder (11.8\%) had completed three-year programs training. Few continuing education opportunities are available. Equipment repair is 
47 available in more facilities $(83 \%)$ than routine maintenance $(63 \%)$ and is complicated by the 48 diversity of brands employed. A total of $93 \%$ of the labs participate in the quality control 49 program run by the National Lab.

$50 \quad$ Conclusion

51 The establishment of an effective national laboratory system requires coordination and 52 input from many areas, including regulation of the sector, training of the technicians, sound 53 infrastructure (including a stable supply of electricity) and dependable communications. 54 Achieving this in developing countries will only be possible if different actors, national and 55 international, coordinate their efforts.

56

57 Keywords: developing countries, clinical laboratory, network

58

59

60

61

62

63

64

65

66

67

68

69 
Clinical laboratory system in Haiti

\section{Introduction}

Developing countries have a heavy burden of both communicable and non-communicable diseases requiring concerted actions to try and limit their spread (1). One of the major hindrances in fighting infectious diseases in developing countries is their limited laboratory capacity, an element critical for the appropriate diagnosis and treatment of patients (2). In the 2008 Declaration of Maputo, the governments of 33 countries and many international health agencies recognized the important role of clinical laboratories in health care and recommended that governments develop national laboratory policies and strategic plans for their implementation (3)(4).

In Haiti, two years after the Declaration of Maputo, the National Laboratory of Public Health (LNSP: Laboratoire National de Santé Publique-) in collaboration with its associated partners, developed a National Strategic Plan 2010-2015. This was followed in 2015 by a National Laboratory Policy. Through a partnership between the public LNSP and GHESKIO which is a private institution (GHESKIO: Groupe Haitien d'Etudes du Sarcome de Kaposi), as well as between institutions northern (Fondation Mérieux, European Commission) and southern hemispheres (Institut Africain de Santé Publique), a new project emerged: SP-Haiti Lab. The focus of this new project was the improvement of clinical laboratories across Haiti. Hence, one of the first objectives of the SP-Haiti Lab is to contribute to elaboration of a new Health Laboratory Policy and the new National Strategic Plan.

As a prelude to preparing long term strategies and policies, the Maputo group advised that situational analyses of the laboratory sectors in each country be undertaken to best adapt strategies to the realities and needs on the ground. In addition, these situational analyses would serve as baselines from which to monitor future progress in the laboratory sector. The aims of 
93 this article are to identify gaps to implementation of a health laboratory system in this developing

94 country and to discuss measures that can address them. In this paper, we perform and describe

95 the situational analysis of laboratories carried out in Haiti: the legal framework in which they are

96 working and the current state of their human resources, infrastructures, and equipment.

\section{$97 \quad$ Methods}

\section{$98 \quad$ Study Setting}

99 The study was performed in Haiti in 30 laboratories from the public and mixed (private/public)

100 sector (Table 1). All of the laboratories chosen are located within Haitian health care institutions

101 throughout the country. A cross-sectional national survey was conducted from January 19 to

102 February 4, 2016.

103

104 Table 1: Distributions of laboratory visited by type and level in the health hierarchy

\begin{tabular}{|c|c|c|c|c|c|c|c|}
\hline \multirow{2}{*}{ Healthcare Institutions } & \multicolumn{5}{|c|}{ Level of Institution } & \multicolumn{2}{|c|}{ Public/Mixed } \\
\hline & HU & HD & HCR & CAL & CSL & Public & Mixed \\
\hline \multicolumn{8}{|c|}{ OUEST } \\
\hline $\begin{array}{l}\text { Hôpital Universitaire de } \\
\text { la Paix }\end{array}$ & $\mathrm{X}$ & & & & & $\mathrm{X}$ & \\
\hline CMS Petite Place Cazeau & & & & $X$ & & & $X$ \\
\hline Hôpital Fermathe & & & & $X$ & & & $X$ \\
\hline \multicolumn{8}{|c|}{ SUD EST } \\
\hline Hôpital Saint Michel & & $X$ & & & & $\mathrm{X}$ & \\
\hline HCR Cayes Jacmel & & & $X$ & & & $\mathrm{X}$ & \\
\hline $\begin{array}{l}\text { Hôpital St Joseph La } \\
\text { Vallée Jacmel }\end{array}$ & & & & $X$ & & & $\mathrm{X}$ \\
\hline
\end{tabular}




\begin{tabular}{|c|c|c|c|c|c|c|}
\hline \multicolumn{7}{|c|}{ SUD } \\
\hline Hôpital IC des Cayes & $\mathrm{X}$ & & & & $\mathrm{X}$ & \\
\hline $\begin{array}{l}\text { Hôpital Ste Anne de } \\
\text { Camn Deprin }\end{array}$ & & & $\mathrm{X}$ & & $\mathrm{X}$ & \\
\hline $\begin{array}{l}\text { Dispensaire Sacré Coeur } \\
\text { de Charpentier }\end{array}$ & & & & $\mathrm{X}$ & & $\mathrm{X}$ \\
\hline \multicolumn{7}{|c|}{ NIPPES } \\
\hline $\begin{array}{l}\text { Hôpital Ste Thérèse de } \\
\text { Miragoane }\end{array}$ & $\mathrm{X}$ & & & & $\mathrm{X}$ & \\
\hline HCR de l'Asile & & $\mathrm{X}$ & & & $\mathrm{X}$ & \\
\hline $\begin{array}{l}\text { Clinique Bethel de Fonds- } \\
\text { des-Nègres }\end{array}$ & & & $\mathrm{X}$ & & & $\mathrm{X}$ \\
\hline \multicolumn{7}{|c|}{ GRANDE ANSE } \\
\hline Hôpital St Antoine Jérémie & $\mathrm{X}$ & & & & $\mathrm{X}$ & \\
\hline $\begin{array}{l}\text { Hôpital Ste Agnès de } \\
\text { Beaumont }\end{array}$ & & & $\mathrm{X}$ & & $\mathrm{X}$ & \\
\hline Sant Lespwa/HHF & & & $\mathrm{X}$ & & & $\mathrm{X}$ \\
\hline \multicolumn{7}{|c|}{ CENTRE } \\
\hline $\begin{array}{l}\text { Hôpital Ste Thérèse de } \\
\text { Hinche }\end{array}$ & $\mathrm{X}$ & & & & $\mathrm{X}$ & \\
\hline $\begin{array}{l}\text { Centre de Santé de } \\
\text { Maissade }\end{array}$ & & & $\mathrm{X}$ & & $\mathrm{X}$ & \\
\hline Clinique St Joseph & & & $\mathrm{X}$ & & & $X$ \\
\hline
\end{tabular}


Clinical laboratory system in Haiti

\begin{tabular}{|c|c|c|c|c|c|c|c|}
\hline \multicolumn{8}{|l|}{ Thomassique } \\
\hline \multicolumn{8}{|c|}{ NORD } \\
\hline $\begin{array}{l}\text { Hôpital Universitaire } \\
\text { Justinien }\end{array}$ & $X$ & & & & & $X$ & \\
\hline Hôpital de Milot & & & & $\mathrm{X}$ & & & $X$ \\
\hline Hôpital Saint Jean Limbé & & & & $X$ & & & $\mathrm{X}$ \\
\hline \multicolumn{8}{|c|}{ NORD EST } \\
\hline Hôpital Fort Liberté & & $\mathrm{X}$ & & & & $\mathrm{X}$ & \\
\hline CS Sainte Suzanne & & & & & $\mathrm{X}$ & $\mathrm{X}$ & \\
\hline CMS Ouanaminthe & & & & $\mathrm{X}$ & & $\mathrm{X}$ & \\
\hline \multicolumn{8}{|c|}{ NORD OUEST } \\
\hline Hôpital IC (Port de Paix) & & $X$ & & & & $X$ & \\
\hline $\begin{array}{l}\text { Hôpital Notre Dame de } \\
\text { la Paix }\end{array}$ & & & $\mathrm{X}$ & & & $\mathrm{X}$ & \\
\hline Centre Médical Beraca & & & & $X$ & & & $X$ \\
\hline \multicolumn{8}{|c|}{ ARTIBONITE } \\
\hline $\begin{array}{l}\text { Hôpital de la Providence } \\
\text { des Gonaives }\end{array}$ & & $\mathrm{X}$ & & & & $\mathrm{X}$ & \\
\hline CS St. Pierre Desdunes & & & & $\mathrm{X}$ & & $X$ & \\
\hline Rhéma Bocozelle & & & & $X$ & & & $\mathrm{X}$ \\
\hline TOTAL & 2 & 8 & 3 & 15 & 2 & 19 & 11 \\
\hline
\end{tabular}


Clinical laboratory system in Haiti

\section{Study population and sampling of the laboratories surveyed}

109 The study population consisted of laboratories from different levels of health care hierarchy: 110 public hospitals (university, provincial hospitals and referral community hospitals), laboratories

111 in public and mixed health centers with and without beds (CALs - clinics with inpatient beds, 112 and CSLs - clinics without inpatient beds, respectively). Sampling was done from a list of 113 known laboratories, with three laboratories selected per department. Therefore, for the 10 114 provinces of Haiti, a total of 30 laboratories were recruited. Out of the 30 laboratories visited, 19 $115(63 \%)$ were from the public sector and $11(37 \%)$ were public/private (mixed). These facilities 116 were further distinguished based on the institutions with which they were associated: 2 were 117 teaching hospitals (HU), 8 were departmental hospitals (HD), 3 were community hospitals 118 (HCR), 15 CALs and 2 CSLs.

120 Explanations for the study were provided to the interviewees. The personnel interviewed 121 included:

122 - The provincial directors of health, hospital directors or the chief physicians and the facility 123 managers in the case of health centers.

124 - Laboratory managers and their teams who facilitated the collection of laboratory information.

125 -LNSP management, who provided the information and documentation needed to describe the 126 institutional and regulatory organization of laboratories in Haiti.

\section{Data collection}

128 Data collection was performed principally by using a survey. This survey was pre-validated in 129 three laboratories at the West Province of Haiti. This survey included both closed and open- 
130

131

132

133

134 135 furniture and brightness.

ended questions. For other questions (e.g., observations), direct observations were performed by investigators. The investigating team was made of national technicians working at the National Laboratory of Public Health and also international technicians from the Mérieux Foundation and the Institut Africain de Sante Publique. The observations of investigators regarding the general conditions were based on the appearance of laboratory roofing, floors, doors, windows, walls,

Data analysis

137 Quantitative data were analyzed using SPSS. Qualitative data were analyzed manually.

\section{Results}

Regulatory texts and strategic documents

141 Investigations described the hierarchical organization of the health sector. At the bottom, are the 142 CALs and the CSLs. On the second level are the community hospitals and on the third level, the 143 provincial hospitals. The Ministry of Health (MOH) 2004 National Strategic Plan for Health 144 Sector Reform highlights the importance of strengthening public health facilities including their 145 laboratories. A five-year strategic plan of the National Network of Laboratories 2010-2015 has 146 been developed. A draft of the National Medical Laboratory Policy of the Republic of Haiti was 147 drafted in March 2015, but has yet to be adopted by the government. Hence a new draft was 148 elaborated and adopted recently in 2018 by the $\mathrm{MOH}$.

\section{Structures working in the field of laboratories} network with a triple mission of: training, diagnosis and research in the field of public health; 


\section{Clinical laboratory system in Haiti}

152 epidemiological surveillance, and; early warning. The LNSP has a close relationship with the 153 Laboratory and Research Epidemiology Department (DELR). The DELR, in turn, is responsible

154 for planning, regulating and coordinating all data received on priority communicable and non-

155 communicable diseases. This data allows the DELR to maintain an early warning system and to 156 promote the integration of prevention and protection activities against these diseases. Besides the

157 LNSP and DELR, others structures in the Ministry of Health (MOH) are also involved in the 158 laboratory sector (e.g., the pharmacy department and professional training departments).

159 Laboratory services

160 Laboratory services routinely performed throughout Haiti include creatinine (70\%), transaminases (50\%), CBC count (77\%), sickling test (70\%), Widal test (87\%), VDRL/RPR

162 (70\%), and malaria test (80\%). None of the labs in our study were able to perform CPK,

163 Hemoglobin electrophoresis, coagulation tests (PT, PTT), detection of Cryptococcus antigen,

164 routine bacterial culture and antimicrobial susceptibility testing (Table 2).

Table 2: Lists of tests by Laboratories

\begin{tabular}{|c|c|c|c|c|c|c|}
\hline \multirow{2}{*}{ Tests } & \multicolumn{6}{|c|}{ Numbers of laboratories doing tests } \\
\hline & HU & HD & HCR & CAL & CSL & Total \\
\hline \multicolumn{7}{|c|}{ Biochemistry } \\
\hline Urea & $2 / 2$ & $7 / 8$ & $1 / 3$ & $9 / 15$ & $1 / 2$ & $20 / 30$ \\
\hline Glucose & $2 / 2$ & $8 / 8$ & $2 / 3$ & $13 / 15$ & $2 / 2$ & $27 / 30$ \\
\hline Creatinine & $2 / 2$ & $7 / 8$ & $1 / 3$ & $10 / 15$ & $1 / 2$ & $21 / 30$ \\
\hline Uric acid & $2 / 2$ & $6 / 8$ & $0 / 3$ & $5 / 15$ & $0 / 2$ & $13 / 30$ \\
\hline
\end{tabular}


Clinical laboratory system in Haiti

\begin{tabular}{|c|c|c|c|c|c|c|}
\hline Calcium & $1 / 2$ & $4 / 8$ & $0 / 3$ & $3 / 15$ & $0 / 2$ & $8 / 30$ \\
\hline Sodium/Potassium & $2 / 2$ & $5 / 8$ & $0 / 3$ & $5 / 15$ & $0 / 2$ & $12 / 30$ \\
\hline Transaminases (AST, ALT) & $2 / 2$ & $6 / 8$ & $0 / 3$ & $8 / 15$ & $1 / 2$ & $15 / 30$ \\
\hline Bilirubin total/Conjuguated & $2 / 2$ & $4 / 8$ & $0 / 3$ & $6 / 15$ & $0 / 2$ & $12 / 30$ \\
\hline Amylase & $0 / 2$ & $1 / 8$ & $0 / 3$ & $2 / 15$ & $0 / 2$ & $3 / 30$ \\
\hline PAL ??? & $1 / 2$ & $1 / 8$ & $0 / 3$ & $2 / 15$ & $0 / 2$ & $4 / 30$ \\
\hline CPK & $0 / 2$ & $0 / 8$ & $0 / 3$ & $0 / 15$ & $0 / 2$ & $0 / 30$ \\
\hline Total Cholestrrol & $2 / 2$ & $7 / 8$ & $0 / 3$ & $8 / 15$ & $1 / 2$ & $18 / 30$ \\
\hline HDL/LDL & $2 / 2$ & $7 / 8$ & $0 / 3$ & $7 / 15$ & $0 / 2$ & $16 / 30$ \\
\hline Triglycerides & $2 / 2$ & $7 / 8$ & $0 / 3$ & $9 / 15$ & $1 / 2$ & $19 / 30$ \\
\hline $\begin{array}{l}\text { Abluminuria and } \\
\text { Glucosuria (urine dip } \\
\text { sticks) }\end{array}$ & $2 / 2$ & $6 / 8$ & $2 / 3$ & $12 / 15$ & $2 / 2$ & $24 / 30$ \\
\hline Total Protein & $2 / 2$ & $4 / 8$ & $0 / 3$ & $5 / 15$ & $0 / 2$ & $11 / 30$ \\
\hline CRP & $2 / 2$ & $5 / 8$ & $1 / 3$ & $5 / 15$ & $0 / 2$ & $13 / 30$ \\
\hline PSA & $0 / 2$ & $2 / 8$ & $0 / 3$ & $1 / 15$ & $0 / 2$ & $3 / 30$ \\
\hline \multicolumn{7}{|c|}{ Hematology } \\
\hline $\begin{array}{l}\text { White and Red Blood cell } \\
\text { count }\end{array}$ & $0 / 2$ & $1 / 8$ & $0 / 3$ & 2/15 & $1 / 2$ & $4 / 30$ \\
\hline Hematocrit & $0 / 2$ & $3 / 8$ & $1 / 3$ & $6 / 15$ & $1 / 2$ & $11 / 30$ \\
\hline Hemoglobin & $0 / 2$ & $3 / 8$ & $1 / 3$ & $6 / 15$ & $1 / 2$ & $11 / 30$ \\
\hline CBC & $2 / 2$ & $7 / 8$ & $2 / 3$ & $11 / 15$ & $1 / 2$ & $23 / 30$ \\
\hline CD4 count & $2 / 2$ & $6 / 8$ & $1 / 3$ & $6 / 15$ & $0 / 2$ & $15 / 30$ \\
\hline VS & $2 / 2$ & $6 / 8$ & $2 / 3$ & $5 / 15$ & $0 / 2$ & $15 / 30$ \\
\hline $\begin{array}{l}\text { Bleeding time/ coagulation } \\
\text { time }\end{array}$ & $2 / 2$ & $6 / 8$ & $3 / 3$ & $8 / 15$ & $0 / 2$ & $19 / 30$ \\
\hline Blood Type & $2 / 2$ & $6 / 8$ & $2 / 3$ & $11 / 15$ & $1 / 2$ & $22 / 30$ \\
\hline
\end{tabular}


Clinical laboratory system in Haiti

\begin{tabular}{|c|c|c|c|c|c|c|}
\hline Emmel Test (Sickling test) & $2 / 2$ & $6 / 8$ & $2 / 3$ & 9/15 & $2 / 2$ & $21 / 30$ \\
\hline Hbg Electrophoresis & $0 / 2$ & $0 / 8$ & $0 / 3$ & $0 / 15$ & $0 / 2$ & $0 / 30$ \\
\hline Coagulation (PT, PTT) & $0 / 2$ & $0 / 8$ & $0 / 3$ & $0 / 15$ & $0 / 2$ & $0 / 30$ \\
\hline \multicolumn{7}{|c|}{ Immuno/serology Tests } \\
\hline Widal test & $2 / 2$ & $7 / 8$ & $1 / 3$ & $14 / 15$ & $2 / 2$ & $26 / 30$ \\
\hline VDRL/RPR & $2 / 2$ & $5 / 8$ & $2 / 3$ & $14 / 15$ & $0 / 2$ & $21 / 30$ \\
\hline ASO & $2 / 2$ & $5 / 8$ & $0 / 3$ & $6 / 15$ & $0 / 2$ & $13 / 30$ \\
\hline HIV & $2 / 2$ & $4 / 8$ & $2 / 3$ & $12 / 15$ & $0 / 2$ & $20 / 30$ \\
\hline Antigen Hbs & $0 / 2$ & $2 / 8$ & $0 / 3$ & $1 / 15$ & $0 / 2$ & $3 / 30$ \\
\hline Pregnancy tests & $1 / 2$ & $6 / 8$ & $1 / 3$ & $11 / 15$ & $2 / 2$ & $21 / 30$ \\
\hline PPD & $1 / 2$ & $5 / 8$ & $1 / 3$ & $5 / 15$ & $0 / 2$ & $12 / 30$ \\
\hline H pylori serology & $1 / 2$ & $7 / 8$ & $2 / 3$ & $8 / 15$ & $1 / 2$ & $19 / 30$ \\
\hline Rheumatoid factor & $0 / 2$ & $1 / 8$ & $0 / 3$ & $1 / 15$ & $0 / 2$ & $2 / 30$ \\
\hline Dengue serology & $0 / 2$ & $1 / 8$ & $0 / 3$ & $0 / 15$ & $0 / 2$ & $1 / 30$ \\
\hline \multicolumn{7}{|c|}{ Parasitology } \\
\hline Stool KOP & $2 / 2$ & $7 / 8$ & $3 / 3$ & $11 / 15$ & $1 / 2$ & $24 / 30$ \\
\hline $\begin{array}{l}\text { Malaria tests( Smears and } \\
\text { RDT) }\end{array}$ & $1 / 2$ & $7 / 8$ & $3 / 3$ & $11 / 15$ & $2 / 2$ & $24 / 30$ \\
\hline Blood Microfflaires & $0 / 2$ & $1 / 8$ & $0 / 3$ & $2 / 15$ & $0 / 2$ & $3 / 30$ \\
\hline Cryptococcus antigen & $0 / 2$ & $0 / 8$ & $0 / 3$ & $0 / 15$ & $0 / 2$ & $0 / 30$ \\
\hline \multicolumn{7}{|c|}{ Bacteriology } \\
\hline Urinary sediment & $0 / 2$ & $5 / 8$ & $1 / 3$ & $6 / 15$ & $1 / 2$ & $13 / 30$ \\
\hline Vaginal smears & $2 / 2$ & $3 / 8$ & $2 / 3$ & $11 / 15$ & $1 / 2$ & $19 / 30$ \\
\hline $\begin{array}{l}\text { CSF cell count and } \\
\text { biochemistry }\end{array}$ & $0 / 2$ & $1 / 8$ & $0 / 3$ & $0 / 15$ & $0 / 2$ & $1 / 15$ \\
\hline
\end{tabular}




\begin{tabular}{|l|l|l|l|l|l|l|}
\hline AFB smears & $1 / 2$ & $2 / 8$ & $2 / 3$ & $7 / 15$ & $0 / 2$ & $12 / 30$ \\
\hline Uroculture + AST & $0 / 2$ & $0 / 8$ & $0 / 3$ & $0 / 15$ & $0 / 2$ & $0 / 30$ \\
\hline Coproculture +AST & $0 / 2$ & $0 / 8$ & $0 / 3$ & $0 / 15$ & $0 / 2$ & $0 / 30$ \\
\hline Hemoculture + AST & $0 / 2$ & $0 / 8$ & $0 / 3$ & $0 / 15$ & $0 / 2$ & $0 / 30$ \\
\hline CSF ( Culture + AST) & $0 / 2$ & $0 / 8$ & $0 / 3$ & $0 / 15$ & $0 / 2$ & $0 / 30$ \\
\hline Expectorated sputum & $0 / 2$ & $0 / 8$ & $0 / 3$ & $0 / 15$ & $0 / 2$ & $0 / 30$ \\
\hline culture & $1 / 2$ & $2 / 8$ & $0 / 3$ & $0 / 15$ & $0 / 2$ & $3 / 30$ \\
\hline Gene Xpert TB & $0 / 2$ & $0 / 8$ & $0 / 3$ & $1 / 15$ & $0 / 2$ & $1 / 30$ \\
\hline Papanicolau (PAP test) & & & & & & \\
\hline
\end{tabular}

\section{Laboratory Facilities}

170 The general conditions of the majority $(83 \%)$ of the premises housing laboratories are deemed 171 satisfactory by investigators, although a variety of deficiencies are described (Table 3).

172 Inconstant supply of electricity (Table 4) does not allow for the lighting and consistently cool

173 temperature necessary for good laboratory practices. To compensate for the irregular supply of 174 electricity by the public network, 86\% (26/30) of the laboratories have a mixed energy input 175 consisting of generators, solar energy and accumulators (Inverters). Eight laboratories (26\%) do 176 not have running water and use cisterns.

178 Table 3: Overview of the premises 179 


\begin{tabular}{|c|c|c|c|}
\hline & insufficient & & \\
\hline Roofing & $5 / 30(16 \%)$ & 25/30 (84\%) & $0 / 30$ \\
\hline Floor covering & $5 / 30(16 \%)$ & 25/30 (84\%) & $0 / 30$ \\
\hline Wall cladding & $8 / 30(26 \%)$ & $22 / 30(74 \%)$ & $0 / 30$ \\
\hline Doors and windows & $6 / 30(20 \%)$ & $23 / 30(76 \%)$ & $1 / 30(3 \%)$ \\
\hline Furniture & $6 / 30(20 \%)$ & $20 / 30(66 \%)$ & $4 / 30(13 \%)$ \\
\hline Benches & $6 / 30(20 \%)$ & $19 / 30$ & $5 / 30(16 \%)$ \\
\hline Lighting & $14 / 30(46 \%)$ & $12 / 30(40 \%)$ & $4 / 30(13 \%)$ \\
\hline Air conditioning & $14 / 30(46 \%)$ & $13 / 30(43 \%)$ & $3 / 30(10 \%)$ \\
\hline Cleanliness of rooms & $5 / 30(16 \%)$ & $23 / 30(76 \%)$ & $2 / 30(6 \%)$ \\
\hline
\end{tabular}

183 Tableau 4: Availability of electricity, water, gas and proper sewerage 


\begin{tabular}{|l|c|c|}
\hline Electricity & $26 / 30$ & $4 / 30$ \\
\hline Electric support & $19 / 30$ & $11 / 30$ \\
\hline (UPS, stabilivers) & $22 / 30$ & $8 / 30$ \\
\hline Water & & \\
\hline Gas & $4 / 30$ & $26 / 30$ \\
\hline Sewers/septic tanks & & $4 / 30$ \\
\hline
\end{tabular}

185 Laboratory staff

186 Profile of the laboratory staff

187 Of the technical staff in the laboratories visited, 26 of the technologists $(11.8 \%)$ have three years 188 of training, $195(88.2 \%)$ have two-year certificates and there are 16 laboratory assistants

189 (bacilloscopists). There were no doctors or pharmacobiologists working in any of the 190 laboratories visited, even at the university hospital level. There is continuing education available 191 at 3 labs (10\%), advanced training or periodic staff evaluation in $3(10 \%)$ laboratories.

\section{Staff supervision}

193 During the previous 12 months, 29 laboratories (96\%) were supervised by different structures 194 such as: LNSP and others NGO working in the health sector (e.g. PEPFAR/CDC); Groupe 195 Haitien d Etude du Sarcome de Kaposi, and Partners in Health. The main problems raised by 196 representatives of these supervisory systems, which are chronic in nature, are: the insufficient

197 numbers of trained personnel; the lack of equipment, reagents and consumable materials; the 
198 199

200

201

202

203

204

205

206

207

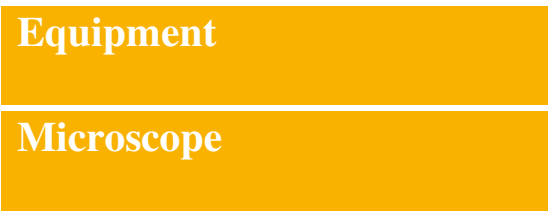

Centrifuge

Spectrophotometer

CBC count machine

CD4 count machine

\section{Total number}

95

54

19

19

15
Number of different brands

15

21

6

3

2

Procurement, storage and management of reagents and consumables materials

211 Public and mixed laboratories receive reagent allocations from the $\mathrm{MOH}$ through programs and

212 partners. The sources of supplies are local private providers and the regional depots where

213 reagents and consumables materials are stored. Eighteen laboratories (60\%) purchase a part of

214 their reagents from their own budget. The storage of reagents is dependent on the supply of 
215 electricity to the laboratories. In 9 laboratories (30\%), the storage of the reagents does not meet

216 the conditions recommended by the manufacturer either due to lack of electricity or inadequate

217 refrigerator temperature monitoring. Stock monitoring occurs regularly in 21 laboratories (70\%),

218 which is reflected in the updated inventory tracking sheets. The method of stock management

219 applied is First Expire First Out (FEFO) in most laboratories. However, 70\% of laboratories

220 reported stock shortages for reagents and consumable materials for periods ranging from 3 days

221 to one year, and the presence of out of date materials was reported in $73 \%$ of laboratories.

\section{Quality assurance management system}

223 There is a national quality assurance program run by the LNSP. In our laboratories sample, 224 internal quality control is implemented in $70 \%$ of the laboratories and $93 \%$ participate in the 225 national quality control program organized by the LNSP. The LNSP procedures manual is 226 available in only $27 \%$ of laboratories visited. Also, only $56 \%$ of the laboratories have a sampling 227 procedure, $30 \%$ a sample receiving procedure, and $40 \%$, cleaning and waste management 228 procedures.

\section{Hygiene, biosafety and laboratory safety}

230 Personal protective equipment is available in most laboratories. To protect the staff and users of

231 the laboratory, a number of instructional documents are displayed, usually pictograms or signs of 232 prohibited practices, procedural requirements or limitations. There is no national program for the 233 protection of health personnel by broad vaccinations. A hepatitis B vaccination initiatives exist 234 in only six laboratories $(20 \%)$. 
Clinical laboratory system in Haiti

235

236

237

238

239

240

241

242

243

244

245

246

247

248

249

250

251

252

253

254

255

256

257

\section{Communication}

Not all laboratories have the necessary communication capabilities: only six laboratories (20\%) have a service phone; $19(63 \%)$ have at least one computer, and 15 (50\%) have internet connection, even if it is irregular. For data management, 18 laboratories (60\%) have a computerized laboratory management systems (LMIS) which is only used for people living with HIV. The LMIS systems in use are OpenElis and ISanté. Only one laboratory uses the LMIS to record and edit all hospitalized patient results.

\section{Role of Laboratory Personnel in the Health System}

Personnel from only 11 laboratories participate in patient care meetings. Laboratory staff are included in 8 out of 10 hospital infection control committees. In the case of diagnosis of a microorganism with epidemic potential, $21(70 \%)$ laboratories communicate the information to the national health system. The majority $(90 \%)$ of laboratories refer to the LNSP for specific pathogens. The routine transfer of aggregated epidemiological data is not systematic, with only 13 laboratories (43\%) sharing data.

\section{Discussion}

Effective clinical laboratories play an essential role in the health care system by providing the data that guide treatment of infectious and non-infectious illness. Unfortunately, the lab sector in developing countries is often neglected (5). Regardless of the levels of interest, creating and supporting a laboratory system in resource limited settings presents many challenges. Developing national laboratory policies and strategies has been recommended to help streamline processes (4). These elements form the keystone supporting the establishment of a laboratory system that can help a country handle health threats (5). As a first step, it is important 
258 to conduct situational analyses of the laboratory sector to assure that planning reflects the 259 realities and needs on the ground. We have conducted such an analysis through surveys and 260 investigations and identified the structure and state of clinical laboratory medicine in Haiti, its 261 strengths and the many challenges it confronts.

\section{Regulation of the laboratory sector}

264 The main objective of the SP-Haiti Lab is to help the MOH and its international partners produce 265 a new National Health Laboratory Policy, to be followed-up by the National Strategic Plan and, 266 finally, the Operational Plan. At the end of these activities, new tools will be available to define 267 both the general approach and specific conduct of the laboratory sector in Haiti. The different 268 actors working in the field of public health have the responsibility of delivering the highest 269 quality service possible for the population, and to use resources rationally. Accordingly, good 270 governance is a key component of to achieving an effective service (6) and strengthening the

271 health care system as a whole (7). Once established, it will be important to make certain that the 272 regulations are implemented. Effective implementation will depend on the support of national 273 leadership and partners from international institutions. This task may not be easy as it known that 274 collaborative governance is sometimes difficult to establish in developing countries due to weak 275 central authority, limited institutional infrastructures and insufficient resources(8).

\section{Structures in the field of clinical laboratories}

277 One of the most significant achievements in Haitian laboratory medicine was the 2006 creation 278 of the LNSP. The lack of an enforceable national laboratory policy, however, continues to 279 undermine the development of a LNSP-led national network in Haiti. Without such a framework, 
280 it is difficult to determine which problems to prioritize while apportioning limited resources and 281 how to assure that policies are observed (9). These issues get more complex when you consider

282 funding and governance. For example, to encourage a more centralized approach, the LNSP has

283 developed a strategy urging regional technicians to conform more to national standards. Yet

284 these technicians are often paid by international partners, making it hard to enforce compliance

285 with national guidelines in any predictable or long-term manner. This begs the larger question of

286 the paradox of international aid. Since, public health sector funding in developing countries is

287 often insufficient, aid from the international community are important (10) and contributes to

288 increase life expectancy (11). However, this can undermine the central authority. Also, foreign

289 assistance can have a negative impact upon national government expenditures on the health

290 sector. For example, for every \$1 USD, governments in developing countries may decrease

291 contributions between $\$ 0.43$ and 1.14 (12) (10)

\section{Services, infrastructure and laboratory housing}

293 It remains a major weakness that routine culture and antimicrobial susceptibility testing is not

294 performed in Haitian labs. Although reliance on clinical assessment for diagnosis and 295 management remains a mainstay of medical practice, particularly in developing countries (e.g.

296 cholera in Haiti)(13), purely clinical algorithms can be flawed and lead to inappropriate and 297 excessive treatment. These issues are illustrated by a study from Ghana in which 251 children 298 were admitted to the hospital with a clinical diagnosis of malaria (based upon WHO criteria). 299 Nevertheless, 69/251 children (27\%) had negative malaria smears but $40 \%$ of the children had 300 bacteremia confirmed by blood cultures. Moreover, 13\% of 182 children with positive malaria 301 smears had concurrent bacterial sepsis while mortality was highest in patients with clinically 302 diagnoses malaria, a negative malaria smear and bacterial sepsis (14). This underscores the 
Clinical laboratory system in Haiti

303 importance of routine bacterial culture and susceptibility testing to support clinical diagnoses and 304 inform antimicrobial coverage.

306 Although investigators felt the majority of the structures housing laboratories are satisfactory,

307 they have also listed numerous significant deficiencies. There is, however, no standardized lab

308 design and an absence of certain spaces that are essential for good practices, such as sampling 309 rooms (absent in 30\% of laboratories), laundries (absent in 77\% of laboratories) and, toilets for 310 staff (absent in 57\% of laboratories). Nevertheless, studies conducted in eight countries have 311 shown that infrastructures ( amenities, equipment, and available medications) are not necessarily 312 related to quality of care: health care services with the same level of infrastructure can deliver a 313 range of different quality care (15).

\section{$314 \quad$ Laboratory staff}

315 Only the LNSP is run by a clinical pathologist. All of the others laboratories, including those in 316 teaching hospitals, are run by laboratory technologists most of whom have completed only 2 year 317 training programs. Regardless of whether this level of training is sufficient, this reality can lead 318 clinicians to question the credibility of laboratory results. (16). Moreover, state accreditation for 319 technicians is difficult because of the lack of standardized curricula or oversight from qualified 320 professors in diverse programs. Since 2011, the LNSP, in collaboration with the Mérieux 321 Foundation has offered a bachelor's degree in medical sciences, but this program only accepts 322 around 18 students per year due to funding issues. The expansion of this training could assure 323 sustainable, comprehensive and standardized training on a national level. Robust continuing 324 education, so important in developed countries, has yet to develop in Haiti but is another 325 important long-term goal (17) . 
Clinical laboratory system in Haiti

\section{Equipment}

The great diversity of laboratory equipment brands creates barriers for proper maintenance. In fact, most of the equipment in labs has been provided by Haiti's partners in an uncoordinated manner, with no maintenance plans in place. To address this problem, donation charters should be developed that take into account the country's willingness to master the diversity of brands, with assistance, and hence properly maintain important laboratory equipment. This chart could follow the WHO recommendations for donations (18). The $\mathrm{MOH}$, however, must then be prepared to fill in gaps that can occur when the rejection of donation creates shortages that could jeopardize public health. The presence of so many different brands also highlights the importance of instituting a process to harmonize the country's clinical laboratory reporting. This would make it possible to compare results from different procedures, facilitating patient management and the application of guidelines (19).

Finally, better servicing of equipment might prevent breakdown. The maintenance system, currently provided by the LNSP (Biomedical Unit), laboratory staff (routine maintenance) and equipment suppliers, is a key element in healthcare. It has been shown that $40-70 \%$ of medical devices and equipment in developing countries have issues related to function: broken, unused or unfit for purpose (20). It is also important to keep in mind that approximately $66 \%$ of equipment out-of-service could be put back into service with a basic knowledge. Hence, giving technicians basic knowledge and training can make a difference (21) .

\section{Procurement, storage and management of reagents and consumable materials}

Besides the modest amounts of reagents some laboratories are able to purchase, most public and mixed laboratories receive reagents from partners. This underlines the strong dependence of Haitian labs on outside support. Although many developing countries are dependent on 


\section{Clinical laboratory system in Haiti}

349 international health care aid, much of the actual funding comes through vertical programs and 350 does not contribute to a global upgrade of the health care system (22). In fact, the laboratory 351 system in Haiti is quite resilient as evidenced by the few shortages in essential reagents observed

352 in laboratories. In order to establish a sustainable and efficient long-term supply system, it would

353 be helpful to adopt a specific budget line for laboratory funding within the state healthcare 354 budget. In addition, the inconsistent supply of electricity, also threatens the availability of these 355 essential chemicals. Other forms of modern energy, like solar power could be developed as an 356 option (23).

357 It is important for stakeholders to understand that the laboratory sector is a national health 358 necessity that must be run by the government and cannot be at the mercy of benevolent strangers 359 (19). To realize this sustainability, the $\mathrm{MOH}$ should assume its leadership role in trying to solve 360 problems of supply chain management in Haiti, by targeting the specific weaknesses identified 361 by the situational analysis (24).

363 Laboratory analysis activities

\section{Quality assurance system}

365 The national laboratory quality assurance program run by the LNSP should be strengthened in 366 order to better coordinate and guide lab function. Strengthening the laboratory evaluation process 367 using the evaluation grid published in 2014 would enable the establishment of a National 368 Laboratory Quality Label System that could be modeled on the WHO Afro SLIPTA process 369 (25). Mentorship of laboratory personnel through short class sessions linked to site supervisions 370 as well as coaching for specific problems could result in improved lab capacity and performance 371 and guide the various labs toward national accreditation (26). Improvements in information 
372 technology (e.g. computers or internet access) would be a major step in promoting effective

373 quality assurance systems. The absence of such technological improvements means that labs

374 must continue to rely on traditional mentoring approaches which require funding for travel, etc.

375 and may, ultimately, be more costly and less effective. A more specific quality assurance

376 question is the decision of whether to buy or prepare chemical and microbiologic panels: the

377 former approach presenting financial challenges and the latter, technical ones.

\section{Hygiene, biosafety and safety at the lab}

379 Most labs have personal protection equipment, but we must work to target $100 \%$ availability. A 380 key element to improving hygiene, biosafety, and safety in labs is the designation of a champion 381 who should address staff education and proficiency monitoring (27). It is also important that 382 technicians be trained in the risks of infectious diseases transmission, and how to handle 383 infectious and biohazard products (28) because in some developing countries, up to $95 \%$ of 384 laboratory technicians may have poor knowledge of biosafety (27). A further goal should be to 385 upgrade labs to the level required by international health regulations, which could also provide 386 an opportunity to promote hygiene, biosafety and overall lab safety (29). There is also no 387 national program for the protection of health care personnel by vaccination. Few hepatitis B 388 vaccination initiatives exist in Haitian laboratories even though HBV infection is well-known 389 risk to laboratory personnel. A routine personnel vaccination program against this virus should 390 be put in place (30).

\section{Communication}

392 Communication between the laboratory technicians and clinicians is important to patient care as $39360-70 \%$ of health care decisions are based on laboratory results. In the case of critical ill patients, 
394 it is essential that this communication be swift as well (31). A valuable first step in this process

395 would be to provide lab personnel and clinicians with the means to communicate more 396 efficiently through phone calls, internet or others modalities. As discussed earlier, even when

397 contact is made, however, the difference in levels of education between clinicians and laboratory 398 technicians may lead the former to question the credibility of the results, which could undermine 399 patient care (16). This further supports the need for accreditation and continuing education for 400 laboratory personnel. Yet it is also important to understand the communications barriers between 401 clinician and laboratory team by conducting studies and workshops that could help appreciate the 402 other's concerns and perspectives. These challenges can have benefits not only for individual 403 patient care, but also for the implementation of public health programs, like the antimicrobial 404 stewardship program (27).

\section{The Role of the Laboratory in the Health System}

406 At an individual healthcare facility level, the laboratory has an important role for diagnosis and 407 treatment. As we have discussed, reliance on clinical assessment alone has pitfalls. It has been 408 shown, in fact, that basic laboratory tests in rural centers in developing countries yield a change 409 of diagnosis and treatment in $45 \%$ of patients (32). In developed countries, it is assumed that the 410 contribution of the laboratory is generally higher, around the " $70 \%$ claim" rule (33). This 411 contribution is particularly true when infectious diseases are involved, and in the face of 412 nosocomial infection outbreaks (33).

413 The lab also plays a central role in national epidemiologic surveillance. It was, in fact, through 414 the efforts of the LNSP that in 2010, two days after the MOH was notified of the first cases of 415 diarrhea, a confirmation of $V$. cholerae serogroup O1, biotype Ogawa was established (34). 
416 Further study revealed the Nepalese origins of this strain (35). The lab also plays follows the

417 ongoing progress in the elimination of malaria in Haiti (36).

418 One of the major, long-term health sector challenges is the integration of all public and private

419 clinical, food safety and environmental laboratories into a cohesive, collaborative system 420 working together to improve public health and quality of care. Information sharing between 421 different layers and actors in the system which will positively impact healthcare (37). It is also 422 important to recognize that the introduction of new laboratory technologies in the public sector 423 does not always lead to better patient outcomes. Rather, the integration of new technologies and 424 protocols should be supported by the best available evidence (38)(27). Finally, it is important 425 reflect on what type of lab services and policies are most suitable for Haiti and other developing 426 countries: point of care testing for remote areas or centralized laboratories with a network system 427 of reference; technicians broadly trained or with narrow specialization; laboratories with more 428 autonomy and flexibility or traditional dependence; laboratories that are more open to 429 participation in international research with developed countries (with opportunities for funding 430 and acquisition of expertise), or laboratories that close the door to this option because of their 431 inherent vulnerabilities and the inapplicability of the results for their population. (39).

\section{Strengths and limitations}

433 This is, to the best of our knowledge, the first study to give an overview of the clinical lab sector 434 in Haiti. The study did not include private labs (of which there are possibly 256) which represent $43544 \%$ of the laboratory sector, so it is unknown how these labs function, what they perform and 436 how they contribute to this sector. Also, no interviews were conducted with patients or 437 physicians whose opinions could give us another perspective on the lab sector in Haiti. 438 Nonetheless, we feel this study can help us understand the general laboratory landscape and 
439 define and prioritize problems that should be addressed through a national laboratory policy and

440 the national strategic plan.

441 Conclusion

442 The development of a clinical laboratory system in a resource limited country is a 443 complex but essential element to improving health care and reducing mortality. Multiple 444 challenges must be overcome to enhance the clinical laboratory sector in Haiti: economic, 445 political, and those of governance. Since the National Laboratory in 2010, many new promising 446 initiatives have taken place: definition of a national network of laboratories; drafting of 447 regulations, and implementation of a quality assurance system. However, many practical and 448 chronic problems remain, including: proper training, equipment shortages, supply chain 449 management, energy and electricity deficiencies, etc. Nevertheless, there is continued support 450 from the Haitian Government and national and international partners. There is also greater 451 integration of others stakeholders, such as universities, professional associations, and distributors 452 of reagents all of whom wish to be a part of the process of building a national laboratory system 453 and improving clinical laboratory medicine in Haiti.

455 List of abbreviations

456 CAL: clinics with inpatient beds

457 CSL: clinics without inpatient beds

458 DELR: Laboratory and Research Epidemiology Department

459 FEFO: First Expire First Out

460 GHESKIO: Groupe Haitien d'Etudes du Sarcome de Kaposi

461 HCR: Referral hospital 
Clinical laboratory system in Haiti

462 HD: District hospital

463 HU: University hospital

464 LNSP: Laboratoire National de Santé Publique

465 MOH: Ministry of Health

466

467 Declarations

468

469 Ethics approval and consent to participate

470

This study was considered as a Non-Human Subject Research and hence approval for this

471 study by an Institutional Review Board was not required by Haitian law (Executive order

472 published at the Haitian official journal "Le Moniteur" on December 23, 1999). The Haiti Ethical

473 Review Committee also considered this activity to be non-research. It was included as part of

474 routine laboratory supervision activities performed by the National Laboratory of Public Health.

475 Furthermore, this work was approved by the Ministry of Health of Haiti and investigators

476 followed the ethical principles for non-human subject research projects (e.g., Informed consent,

477 Privacy and confidentiality protections). Verbal informed consent was obtained for all

478 participants, because with this research there was no more than minimal risk of harm to subjects

479 during the meeting/survey. All methods were carried out in accordance with relevant guidelines 480 and regulations.

481

482 Consent for Publication

483 Not applicable 


\section{Availability of data and materials}

486 The datasets used and/or analyzed during the current study are available from the corresponding 487 author on reasonable request.

489 Competing interests

490 There's no competing interests involved in this study for any of the authors of this article.

491

\section{$492 \quad$ Funding}

493 This research was supported by the SP-Haiti Lab project

\section{Author contributions}

496 M.L., J.S., C.M., G.A.J., P.A., S.K., E.L., J.B., J.B, P.D., M.S. were in charge of the 497 conceptualization and methodology of the study. J.S, C.M., M.C and E.L participated in the 498 field survey; M.L. and J.S were involved in data curation and formal analysis; M.L, J.S, S.K., 499 M.F.C, D.M.P, G.M., L.M.K., M.J.Z., P.E.K wrote the main manuscript text. All authors 500 reviewed the manuscript.

501

\section{Acknowledgements}

503 We would like to thank all those who gave us their help within the various institutions on which 504 this study was carried out.

505

\section{References}


508 1. Bygbjerg IC. Double burden of noncommunicable and infectious diseases in developing

509

510

511

512

513

514

515

516

517

518

519

520

521

522

523

524

525

526

527

528

529

530 countries. Science [Internet]. 2012 Sep 21 [cited 2018 Dec 25];337(6101):1499-501.

Available from: http://www.ncbi.nlm.nih.gov/pubmed/22997329

2. de Lamballerie X, Colson P. The battle against infectious diseases in developing countries: the inseparable twins of diagnosis and therapy. Clin Chem [Internet]. 2006 Jul 1 [cited 2018 Dec 25];52(7):1217. Available from:

http://www.ncbi.nlm.nih.gov/pubmed/16798963

3. Nkengasong JN. Strengthening Laboratory Services and Systems in Resource-Poor Countries. Am J Clin Pathol [Internet]. 2009 Jun 1 [cited 2019 Mar 17];131(6):774-774. Available from: https://academic.oup.com/ajcp/article/131/6/774/1760396

4. The Maputo The Maputo The Maputo The Maputo Declaration Declaration Declaration Declaratio The Maputo Declaration on Strengthening of Laboratory Systems. [cited 2017 Jul 2]; Available from: http://www.who.int/diagnostics_laboratory/MaputoDeclaration_2008.pdf

5. Nkengasong JN, Skaggs BA. Are post-Ebola reconstruction efforts neglecting public health laboratory systems? Lancet Glob Heal [Internet]. 2015 Nov 1 [cited 2019 Mar 17];3(11):e678. Available from:

https://linkinghub.elsevier.com/retrieve/pii/S2214109X1500159X

6. Trenti T, Canali C, Scognamiglio A. Clinical Governance and evidence-based laboratory medicine. Clin Chem Lab Med [Internet]. 2006 Jan 1 [cited 2018 Dec 25];44(6):724-32. Available from: http://www.ncbi.nlm.nih.gov/pubmed/16729861

7. Bertoncello C, Buja A, Silenzi A, Specchia ML, Franchino G, Lazzari A, et al. Good governance competencies in public health to train public health physicians. Int J Public 
Clinical laboratory system in Haiti

Health [Internet]. 2015 Sep [cited 2018 Dec 25];60(6):737-49. Available from: http://www.ncbi.nlm.nih.gov/pubmed/26159093

8. Emerson K. Collaborative governance of public health in low- and middle-income countries: lessons from research in public administration. BMJ Glob Heal [Internet]. 2018 Oct 1 [cited 2018 Dec 25];3(Suppl 4):e000381. Available from: http://gh.bmj.com/lookup/doi/10.1136/bmjgh-2017-000381

9. Development of National Health Laboratory Policy and Plan [Internet]. 2011 [cited 2018 Dec 25]. Available from: http://www.wpro.who.int/health_technology/documents/docs/Nationalhealthlab2_0F38.pd $\mathrm{f}$

10. De Maeseneer J, van Weel C, Egilman D, Mfenyana K, Kaufman A, Sewankambo N, et al. Funding for primary health care in developing countries. BMJ [Internet]. 2008 Mar 8 [cited 2018 Feb 20];336(7643):518-9. Available from: http://www.ncbi.nlm.nih.gov/pubmed/18325939

11. Bendavid E, Bhattacharya J. The Relationship of Health Aid to Population Health Improvements. JAMA Intern Med [Internet]. 2014 Jun 1 [cited 2019 Mar 17];174(6):881. Available from:

http://archinte.jamanetwork.com/article.aspx?doi=10.1001/jamainternmed.2014.292

12. Lu C, Schneider MT, Gubbins P, Leach-Kemon K, Jamison D, Murray CJL. Public financing of health in developing countries: a cross-national systematic analysis. Lancet (London, England) [Internet]. 2010 Apr 17 [cited 2018 Mar 6];375(9723):1375-87. Available from: http://www.ncbi.nlm.nih.gov/pubmed/20381856

13. Lucien MAB, Schaad N, Steenland MW, Mintz ED, Emmanuel R, Freeman N, et al. 
Identifying the most sensitive and specific sign and symptom combinations for cholera: Results from an analysis of laboratory-based surveillance data from Haiti, 2012-2013. Am J Trop Med Hyg. 2015;92(4):758-64.

14. Evans JA, Adusei A, Timmann C, May J, Mack D, Agbenyega T, et al. High mortality of infant bacteraemia clinically indistinguishable from severe malaria. QJM [Internet]. 2004 Sep 1 [cited 2019 Feb 3];97(9):591-7. Available from: http://www.ncbi.nlm.nih.gov/pubmed/15317928

15. Leslie HH, Sun Z, Kruk ME. Association between infrastructure and observed quality of care in 4 healthcare services: A cross-sectional study of 4,300 facilities in 8 countries. Persson LÅ, editor. PLOS Med [Internet]. 2017 Dec 12 [cited 2018 Mar 6];14(12):e1002464. Available from: http://dx.plos.org/10.1371/journal.pmed.1002464

16. Tuijn CJ, Msoka E, Mushi DL, Boer MS, Chilongola J, van den Broek A. The interface between clinicians and laboratory staff: A field study in northern Tanzania. Afr J Lab Med [Internet]. 2014 [cited 2018 Mar 6];3(1):126. Available from: http://www.ncbi.nlm.nih.gov/pubmed/29043178

17. Continuing Education Requirements for Medical Laboratory Professionals in States with Licensure or Certification. [cited 2018 Mar 6]; Available from: https://watermark.silverchair.com/labmed340095.pdf?token=AQECAHi208BE49Ooan9kkhW_Ercy7Dm3ZL_9Cf3qfKAc485ysgAA AbAwggGsBgkqhkiG9w0BBwagggGdMIIBmQIBADCCAZIGCSqGSIb3DQEHATAeB glghkgBZQMEAS4wEQQMUbhaVIOATZ6ykvieAgEQgIIBY1J6rVWCNVrgtJw8y8y76 FkLq8rm7OPkcedhKVvpEKSpkbq5TfpfR9Eyio6OdAS1zZGkm2ub86gZv81tZtFYXGmwMU- 
VIUeyZITrDAGNTKwongK0FTE6P5vVOM3Sad7YStCQyFSzZvF0Jg_ZybIVaxx9rkAs TPYCbHF35722X88jbxvSdOWUzXh3a5kPRbDzpuxqEgjJHoTBN8ceEnYCpDyy76wrN G_nLC_ifhP5r4NwKOWOUtqWu-y_38sp0FBcF6PvJzokKbmFye_AreeT9Moy3RhTC9hDcPR2wpjHE1iUrTIIM6La4Wln6QAQCsMXaZ6YyKbgxJnmh 167jAlLWOrF_CmrcciDQpYFbp-

RvOrbLI4h1iqFd5DmSm1GKzVCj6FSt_Bt1AuAKipq5xS8xxp3A6IOIaGpNLaxrPOcbk dDpVraJsVAiWVbUDb3U-wqc0v9-0hh4znjXlk-cvbql19k

18. Organization of Health Services Delivery(OSD). 2000 [cited 2018 Mar 6]; Available from: http://www.who.int/medical_devices/publications/en/Donation_Guidelines.pdf

19. WHO | Health and security in foreign policy. WHO [Internet]. 2011 [cited 2019 Feb 3]; Available from: https://www.who.int/bulletin/volumes/85/3/06-036889/en/

20. Diaconu K, Chen Y-F, Cummins C, Jimenez Moyao G, Manaseki-Holland S, Lilford R. Methods for medical device and equipment procurement and prioritization within lowand middle-income countries: findings of a systematic literature review. Global Health [Internet]. 2017 Dec 18 [cited 2018 Mar 6];13(1):59. Available from: http://www.ncbi.nlm.nih.gov/pubmed/28821280

21. Malkin R, Keane A. Evidence-based approach to the maintenance of laboratory and medical equipment in resource-poor settings. Med Biol Eng Comput [Internet]. 2010 Jul 21 [cited 2018 Mar 6];48(7):721-6. Available from: http://www.ncbi.nlm.nih.gov/pubmed/20490939

22. De Maeseneer J, van Weel C, Egilman D, Mfenyana K, Kaufman A, Sewankambo N, et al. Funding for primary health care in developing countries. BMJ [Internet]. 2008 Mar 8 [cited 2018 Mar 6];336(7643):518-9. Available from: 
Clinical laboratory system in Haiti

600

601

602

603

604

605

606

607

608

609

610

611

612

613

614

615

616

617

618

619

620

621

622

http://www.ncbi.nlm.nih.gov/pubmed/18325939

23. Modern Energy Services for Health Facilities in Resource-Constrained Settings. [cited 2018 Mar 6]; Available from:

http://apps.who.int/iris/bitstream/10665/156847/1/9789241507646_eng.pdf

24. Yadav P. Health Product Supply Chains in Developing Countries: Diagnosis of the Root Causes of Underperformance and an Agenda for Reform. Heal Syst Reform [Internet]. 2015 Feb 17 [cited 2018 Mar 6];1(2):142-54. Available from:

https://www.tandfonline.com/doi/full/10.4161/23288604.2014.968005

25. WHO Guide for the Stepwise Laboratory Improvement Process Towards Accreditation (SLIPTA) in the African Region (with checklist) | WHO | Regional Office for Africa [Internet]. [cited 2019 Mar 24]. Available from:

https://www.afro.who.int/publications/who-guide-stepwise-laboratory-improvementprocess-towards-accreditation-slipta-african

26. Yao K, McKinney B, Murphy A, Rotz P, Wafula W, Sendagire H, et al. Improving Quality Management Systems of Laboratories in Developing Countries. Am J Clin Pathol [Internet]. 2010 Sep 1 [cited 2018 Mar 6];134(3):401-9. Available from:

http://www.ncbi.nlm.nih.gov/pubmed/20716796

27. Badrick T. Evidence-based laboratory medicine. Clin Biochem Rev [Internet]. 2013 Aug [cited 2017 Jul 5];34(2):43-6. Available from:

http://www.ncbi.nlm.nih.gov/pubmed/24151340

28. Coelho AC, García Díez J. Biological Risks and Laboratory-Acquired Infections: A Reality That Cannot be Ignored in Health Biotechnology. Front Bioeng Biotechnol [Internet]. 2015 [cited 2018 Mar 6];3:56. Available from: 
Clinical laboratory system in Haiti

623

624

625

626

627

628

629

630

631

632

633

634

635

636

637

638

639

640

641

642

643

644

645

http://www.ncbi.nlm.nih.gov/pubmed/25973418

29. Masanza M, Nqobile N, Mukanga D, Gitta S. Laboratory capacity building for the International Health Regulations (IHR[2005]) in resource-poor countries: the experience of the African Field Epidemiology Network (AFENET). BMC Public Health [Internet]. 2010 Dec 3 [cited 2018 Mar 6];10(Suppl 1):S8. Available from:

http://www.ncbi.nlm.nih.gov/pubmed/21143830

30. Jha AK, Chadha S, Bhalla P, Saini S. Hepatitis B infection in microbiology laboratory workers: prevalence, vaccination, and immunity status. Hepat Res Treat [Internet]. 2012 Dec 4 [cited 2018 Mar 6];2012:520362. Available from:

http://www.ncbi.nlm.nih.gov/pubmed/23304474

31. Montes A, Francis M, Ciulla AP. Assessing the delivery of patient critical laboratory results to primary care providers. Clin Lab Sci [Internet]. 2014 [cited 2018 Mar 6];27(3):139-42. Available from: http://www.ncbi.nlm.nih.gov/pubmed/25219070

32. Carter JY, Lema OE, Wangai MW, Munafu CG, Rees PH, Nyamongo JA. African journal of laboratory medicine. [Internet]. Vol. 1, African Journal of Laboratory Medicine. AOSIS OpenJournals; 2012 [cited 2019 Feb 2]. 6 p. Available from:

https://ajlmonline.org/index.php/ajlm/article/view/8/61

33. Hallworth MJ. The "70\% claim": what is the evidence base? Ann Clin Biochem [Internet]. 2011 Nov 1 [cited 2019 Feb 2];48(6):487-8. Available from: http://acb.sagepub.com/lookup/doi/10.1258/acb.2011.011177

34. Centers for Disease Control and Prevention (CDC). Cholera outbreak --- Haiti, October 2010. MMWR Morb Mortal Wkly Rep [Internet]. 2010 Nov 5 [cited 2019 Feb 2];59(43):1411. Available from: http://www.ncbi.nlm.nih.gov/pubmed/21048563 
646 35. Orata FD, Keim PS, Boucher Y. The 2010 Cholera Outbreak in Haiti: How Science

647

648

649

650

651

652

653

654

655

656

657

658

659

660

661

662

663

664
Solved a Controversy. Heitman J, editor. PLoS Pathog [Internet]. 2014 Apr 3 [cited 2018

Mar 6];10(4):e1003967. Available from: http://dx.plos.org/10.1371/journal.ppat.1003967

36. Adrien P, Jacques Boncy P, Frantz Lemoine J, Existe A, Juin S, Amouzou S, et al.

Malaria Elimination in Haiti: Challenges, Progress and Solutions. Clin Microbiol Infect

Dis [Internet]. 2016 [cited 2018 Mar 6];1(2). Available from: https://oatext.com/Malaria-

Elimination-in-Haiti-Challenges-Progress-and-Solutions.php

37. Marshall SA, Charles Brokopp MD, Tim Size D. Leadership Principles for Developing a Statewide Public Health and Clinical Laboratory System. 2010 [cited 2018 Mar 6];125(2). Available from: http://journals.sagepub.com/doi/pdf/10.1177/00333549101250S214

38. Albert H, Nathavitharana RR, Isaacs C, Pai M, Denkinger CM, Boehme CC.

Development, roll-out and impact of Xpert MTB/RIF for tuberculosis: what lessons have we learnt and how can we do better? Eur Respir J [Internet]. 2016 Jul 13 [cited 2019 Feb 3];48(2):516-25. Available from: http://www.ncbi.nlm.nih.gov/pubmed/27418550

39. Davies J, Abimiku A, Alobo M, Mullan Z, Nugent R, Schneidman M, et al. Sustainable clinical laboratory capacity for health in Africa. Lancet Glob Heal [Internet]. 2017 Mar 1 [cited 2019 Mar 19];5(3):e248-9. Available from:

http://www.ncbi.nlm.nih.gov/pubmed/28108137 


\section{Supplementary Files}

This is a list of supplementary files associated with this preprint. Click to download.

- Survey.doc 